Mecklenburg's results show in accordance with Lord Rayleigh's law that for very small particles the Tyndallmeter reading increases proportionally to the cube of the particle diameter. They also show, however, that at a diameter of $8.40 \times \mathrm{ro}^{-5} \mathrm{~cm}$. the Tyndallmeter reading is still increasing with size of sulfur particle while our results which begin where his leave off show that at this size of silica particle the Tyndallmeter readings are decreasing with increasing diameter. This discrepancy is further emphasized by our results with smokes which, although only qualitative in nature, nevertheless show definitely that even for much smaller particles Tyndallmeter reading decreases at a given concentration with size of particles.

Further investigations on dispersoids, bridging the gap between the region where Lord Rayleigh's law holds and the region where Tyndallmeter reading is proportional to total reflecting surface would be desirable.

WAGHINGTON, D. C.

\title{
AN ELECTRICAL PRECIPITATOR FOR ANALYZING SMOKES.
}

By Richard C. Torman, L. H. Reyerson, A. P. Brooks and H. D. SMrth. Received January 17, 1919.

The following note presents a description of an electrical precipitating apparatus for determining the concentration of smokes. The apparatus was developed by the Dispersoid Section, Research Division, Chemical Warfare Service. ${ }^{1}$

The purpose of the work was to obtain a general form of apparatus which could be used for the analysis of any smoke independent of its chemical nature. The apparatus consists essentially of a modified Cottreil precipitator, with a central wire as cathode surrounded by a cylindrical foil as anode. The smoke to be analyzed is drawn through the apparatus at a known rate and the particles of smoke precipitated on the foil by means of a high voltage, direct current. The determination of concentration is made by measuring the volume of air that passes through the apparatus and weighing the foil before and after precipitation.

The most important consideration to be kept in mind in designing such an apparatus is to make the foil very light, so that the precipitated material shall form as large a fraction as possible of the total weight. For this reason we used aluminum foil o.oor inch in thickness. Thin tin foil was tried but was easily torn in handling and did not have spring enough to keep it cylindrical in shape. This latter point is very important, since a distortion of the cylindrical form leads to sparking instead of the desired corona discharge.

A second consideration to keep in mind, in the design of the apparatus,

1 The publication of this note has been authorized by Major-General William $\mathfrak{I}$. Sibert, Chief of Chemical Warfare Service, U. S. A. 
is the desirability of using as high voltages as possible in order to permit a rapid removal of the sample and still maintain complete precipitation. The higher the voltage, however, the greater is the danger of sparking, and such sparking interrupts the corona discharge and interferes with the operation of the apparatus which depends for its action on a regular flow of electrons from the cathode and a regular electric field which will carry the negatively charged smoke particles to the anode.

To prevent sparking the wire must be centered carefully and should be as fine as possible. We have also found it advantageous, following a

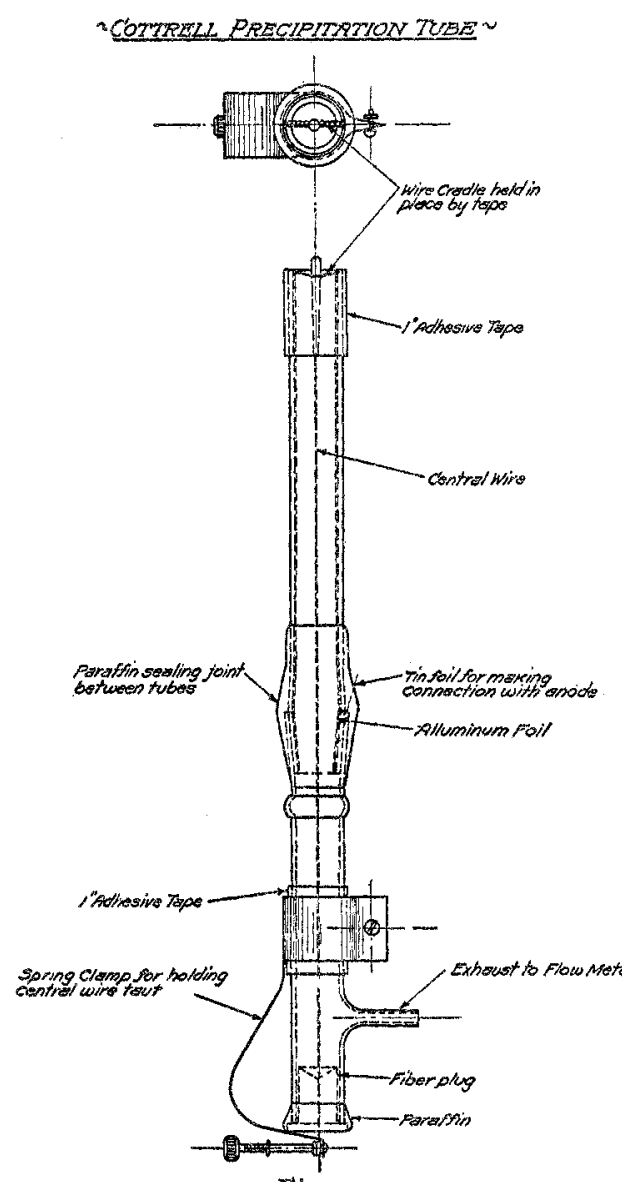

Fig. I. suggestion of Lieut. Col. Arthur B. Lamb, to thread the wire, since sparking occurs more readily from a smooth than from a threaded wire. We now use for this purpose a. No. 25 platinum wire, threaded with a jeweler's die. Wires of oxidizable material are very short-lived owing to the ozone present in the discharge.

The actual arrangement of the apparatus is shown in Fig. $x$. It consists essentially of a glass tube $5 / \mathrm{s}^{\prime \prime}$ in diameter and $1 \mathrm{O}^{\prime \prime}$ long with a ground-glass joint, the aluminum foil, and the central wire.

To prepare the apparatus for use, the glass tube is separated at the joint and the foil, rolled into a cylinder $6^{\prime \prime}$ long, is then introduced. The joint is closed and paraffined to prevent leakage, and the central wire is then inserted and clamped to the spring which holds it under tension.

Electrical connection with the aluminum is made by a small strip of tin foil that comes out through the ground glass joint. One end of the central wire is held by the clamp and the other end is sealed on to a glass rod which fits into the wire cradle at the end of the tube. After the apparatus is assembled, paraffin is melted into the hole where the wire comes out through the fiber plug. 
Adhesive tape on the end of the tube makes a cylinder just large enough to slip into a rubber tube carrying the desired sample of smoke. After precipitation has taken place, the air passes through a flowmeter to determine the volume of sample taken.

The glass rod which is sealed to the end of the central wire extends somewhat beyond the edge of the aluminum foil thus securing a margin of safety for the deposit of smoke. The appearance of the deposit is 13stally sufficient to show whether complete precipitation has taken place. At the entering end of the foil there is a sharp line of demarcation between the bare foil and the deposit, corresponding to the junction of the central wire and the glass rod. Beyond this line of demarcation, the deposit gradually tapers off leaving a couple of inches of bare foil at the other end.

The high voltage direct current for the operation of the apparatus was obtained by stepping up from ro volts, alternating current, and then rectifying with a General Electric Company "Kenotron." It was possible to use in the neighborhood of 15,000 volts without sparking. A mechanical rectifier for the current was tried in place of the Kenotron but for some reason this led to increased sparking.

In general it was found possible to pull a fairly concentrated sample of smoke through the apparatus at a speed of about 5 liters per minute and obtain complete precipitation.

The use of the apparatus, in following the behavior of smokes, will be considered in a subsequent article.

WASHHGTON, D. C.

[Contributton from the Research Laboratory of Phystcal Chemistry of the MassachusetTs Institute of Technorogy, No. 114.]

\section{THE EQUATION OF STATE FOR LIQUIDS AND VAPORS. $I$. THE VAPOR PHASE OF ETHYL ETHER.}

By Freperick G. Keyes and William A. Felsing.

Received February 8, 1919.

Conisnis.-1. Theoretical Considerations. 2. The Experimental Method. 3. Preparation of the Material. 4. Discussion of the Older Data. 5. The Newly Measured Isometrics of Ethyl Fther. 6. Interpretation of All Experimental Data. Relating to the Vapor Phase. 7. Summary.

\section{r. Theoretical Considerations.}

Many experimental researches have been carried out for the purpose of stpplying data bearing on the pressure-volume relation of substances. These researches may be said to have been inspired for the most part by the desire to supply a basis for testing adequately certain equations of state or for providing a more extended body of data upon which, perhaps by purely empirical means, a satisfactory equation might be built up.

The evident importance to steam engineering, refrigerating engineering, 